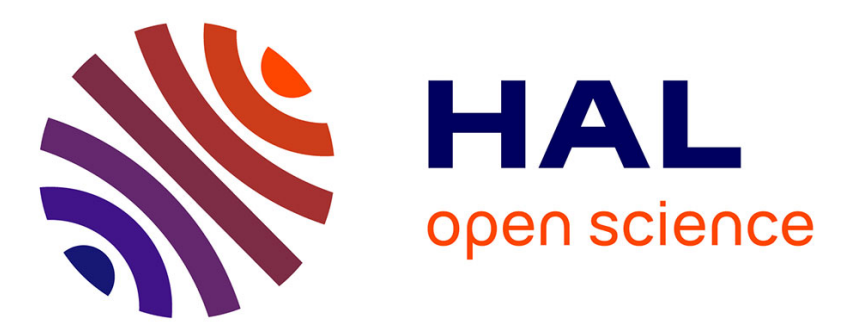

\title{
A practical method to derive sample temperature during nonisothermal coupled thermogravimetry analysis and differential scanning calorimetry experiments
}

\author{
Sylvain Salvador, Jean Henry Ferrasse
}

\section{- To cite this version:}

Sylvain Salvador, Jean Henry Ferrasse. A practical method to derive sample temperature during nonisothermal coupled thermogravimetry analysis and differential scanning calorimetry experiments. Chemical Engineering and Technology, 2006, 29 (6), p.696-702. 10.1002/ceat.200600022 . hal01847589

\author{
HAL Id: hal-01847589 \\ https://hal.science/hal-01847589
}

Submitted on 6 Nov 2018

HAL is a multi-disciplinary open access archive for the deposit and dissemination of scientific research documents, whether they are published or not. The documents may come from teaching and research institutions in France or abroad, or from public or private research centers.
L'archive ouverte pluridisciplinaire HAL, est destinée au dépôt et à la diffusion de documents scientifiques de niveau recherche, publiés ou non, émanant des établissements d'enseignement et de recherche français ou étrangers, des laboratoires publics ou privés. 


\title{
A Practical Method to Derive Sample Temperature during Nonisothermal Coupled Thermogravimetry Analysis and Differential Scanning Calorimetry Experiments
}

\author{
By Sylvain Salvador and Jean-Henry Ferrasse*
}

Nonisothermal thermogravimetry differential scanning calorimetry (TG-DSC) mounting is intensively used for the determination of kinetic parameters and reaction heat along the chemical transformation of a solid. Nevertheless, when tests are performed with heating rates as high as those encountered in industrial processes, e.g., several tens of $\mathrm{K} \mathrm{min}^{-1}$, there is great uncertainty in the knowledge of the exact sample temperature. In this work, a method to derive a simple mathematical expression is proposed and fully described in order to calculate the real sample temperature throughout a temperature-ramped test on a commercial apparatus. The furnace temperature and the heat flow signals were used, together with the crucible specific heat and the heating rate. A number of validation tests were performed to derive similar reaction rates for a reference. Firstorder kinetic reactions were presented and reconciled over a large range of heating rates from 3 to $50 \mathrm{~K} \mathrm{~min}^{-1}$.

\section{Introduction}

Temperature-ramped thermogravimetry (TG) analysis is an efficient way to derive, from a single experiment, kinetic parameters for chemical reactions such as thermal degradation over a wide range of temperature. Coupling mass information to heat flow information additionally facilitates the derivation of the reaction heat associated with the transformation (differential scanning calorimetry (DSC)). For technical reasons, it is difficult in coupled TG-DSC mountings to measure the sample temperature while weighing it continuously with high precision. The temperature is, therefore, usually measured from a thermocouple placed either inside the atmosphere gas or inserted into the furnace wall. However, it is established that there can exist a temperature gap between the furnace and the crucible as high as several tens of degrees. This causes a problem since the relevant temperature for kinetic parameter determination is the sample temperature [1]. High heating rates favor this difference.

A number of technical procedures have been proposed to solve this problem. They are mainly based on different experiments, one for mass recording and some others for tem-

[*] Pr S. Salvador, Laboratoire de Génie des Procédés des Solides Divisés, Ecole des Mines d'Albi-Carmaux, UMR CNRS 2392, Campus Jarlard, route de Teillet, 81013 Albi CT CEDEX 09, France; Dr. J.-Henry Ferrasse (author to whom correspondence should be addressed, jean-henry.ferrasse@univ.u-3mrs.fr), LMNSMGP, UMR CNRS 6181, Université Paul Cézanne d'Aix Marseille 3, Bâtiment Laennec, Hall C, Domaine du Petit Arbois, RD 54 BP, Avenue Louis Philibert, 13545 Aix en Provence Cedex 04, France. perature recording [2,3]. Subramanian [4] proposed a mounting with optical measurement of temperatures, without direct contact of the probe with the crucible. The effect of emissive properties of materials now needs to be investigated more thoroughly to check the reliability of measurements.

In contrast to purely technical solutions, some authors tried mathematical corrections. Sigrist [5] developed a black-box type of model for the heat flowmeter crucible mounting. The author proposes an apparatus transfer function that links melting points of standards (inputs) with the recorded signals during experiments (outputs). The author, nevertheless, notices himself that the apparatus function varies according to the data set used to calculate them. Dong et al. [6] proposed a numerical model using enthalpy as a function of temperature as an input. A temperature is then scanned or modulated. The response of the calorimeter is calculated. This predicts the sample thermocouple temperature and the temperature difference between the sample and reference thermocouples as a function of time and temperature.

In this paper, a practical method is proposed for establishing a simple mathematical expression dedicated to the TGDSC apparatus used, to calculate throughout an experiment the temperature difference, TD, between the sample and the furnace. The method is based on a description of the net heat flow recorded as the sum of a crucible inertia heat flow, a sample inertia heat flow, and a chemical reaction heat flow. The expression is determined from a heat balance over the heat flowmeter, on the one hand, and from a heat balance over the crucible, on the other hand. A simplified heat transfer model is used. As detailed below, it is possible to fit the parameters appearing in the mathematical expression through the reconciliation of the kinetic parameters determined at two different heating rates for a reference chemical reaction. 


\section{Deriving Mathematical Expression}

\subsection{SETARAM TG-DSC 111 Mounting}

The general arrangement of the TG-DSC coupling system used is shown in Fig. 1 (for details, see manufacturer (www.setaram.com)). A similar mounting is placed beside the one represented here (sample mounting), and generally operates with an empty crucible or a reference material (reference mounting). The recorded signals are the temperature measured inside the furnace wall, $T_{\mathrm{f}}$, the crucible plus sample mass, $m_{\mathrm{C}}+m_{\mathrm{S}}$, and the raw heat flow, $\phi_{\mathrm{R}-\mathrm{REC}}$. As detailed further, this flow signal is the difference between the sample heat flow thermopile signal, $\phi_{\mathrm{R}}$, and the reference heat flow thermopile signal, $\phi_{\mathrm{REF}}$.

\subsection{Assumptions}

a) It is assumed that the temperature of the crucible and the temperature of the sample remain identical and equal to

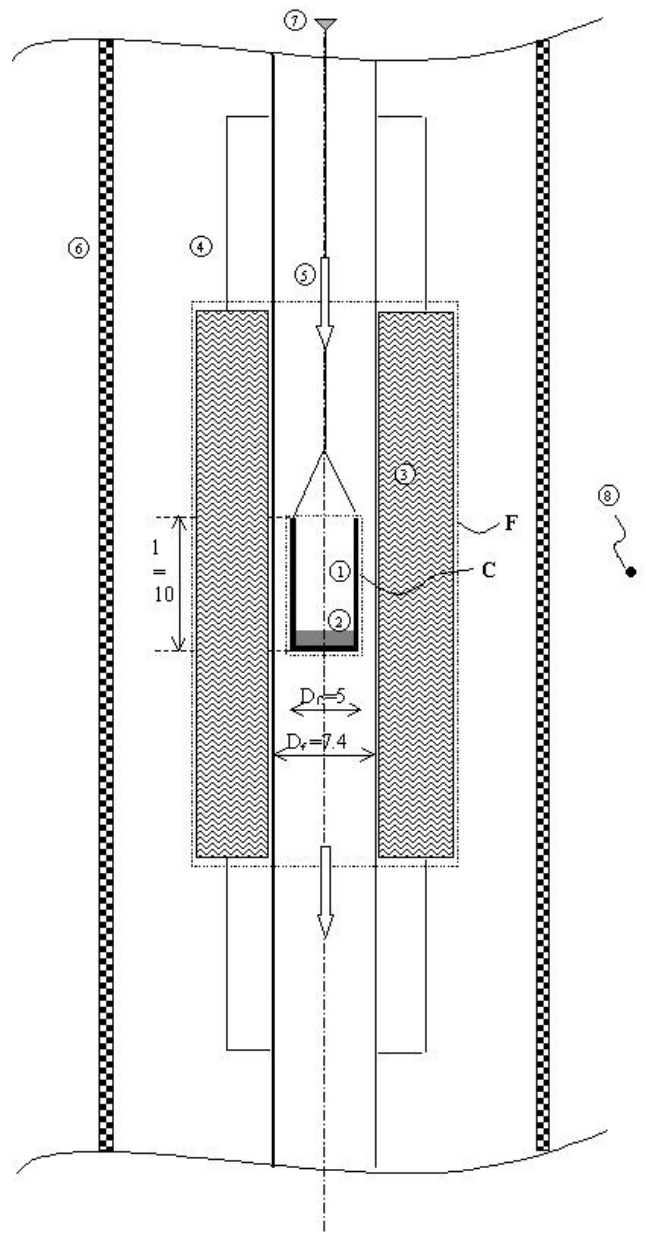

Figure 1. Arrangement of TG-DSC apparatus. (1) crucible, (2) sample, (3) thermopile, (4) furnace, (5) atmosphere gas, (6) heating elements, (7) weighing system, (8) furnace thermocouple. A similar mounting (reference crucible) is located beside this one.
$T_{\mathrm{C}}$. For a detailed calculation based on the thermal Biot number, the reader can refer to [7].

b) Convection heat transfer between the crucible and the furnace is generally supposed to be more efficient than radiation as long as the temperature remains below approximately $500{ }^{\circ} \mathrm{C}$. This was confirmed with the calculation of the global heat transfer coefficient (see annex 1).

c) For the low gas flow rates typically used, the flow inside the furnace is laminar. The heat exchange between the crucible and the furnace can be described as heat conduction through the atmosphere gas film that separates them. The validity of this assumption is stated (see also annex 1). Indeed, the Nusselt number for cocylindrical flow only depends on the diameter ratio and wall boundary [8].

d) The heat flowmeter presents a pure time delay, e.g., its flow signal is time delayed, by $\tau_{\mathrm{HFM}}$ seconds, as compared with the actual heat flow leaving the crucible [9].

\subsection{Mathematical Modeling}

The mathematical modeling is only based on several enthalpy balances.

The enthalpy balance for the flowmeter (domain $F$ in Fig. 1) gives ${ }^{1)}$ :

$\phi_{\mathrm{R}}=\left(M_{\mathrm{D}}+M_{\mathrm{s}}\right) \frac{\mathrm{d} T_{\mathrm{c}}}{\mathrm{d} t}+\phi_{\mathrm{Ch}}+\phi_{\mathrm{g}}$

where $\phi_{\mathrm{R}}$ is the raw heat flow (measured by the sample thermopile), the first term on the right-hand side is the thermal inertia of the crucible + sample, $\phi_{\mathrm{Ch}}$ is the chemical reaction heat flow, and $\phi_{\mathrm{g}}$ is the heat flow resulting from the enthalpy variation of the sweeping gas entering and leaving the domain. The term $\phi_{\mathrm{g}}$ is suppressed by running a blank test in which an empty crucible is heated under the same temperature ramp. During this blank test, the heat flow of the sample thermopile can be expressed as:

$\phi_{\mathrm{B}}=M_{\mathrm{C}} \beta+\phi_{\mathrm{g}}$

In Eqs. (1) and (2), $\phi_{\mathrm{g}}$ can be considered as equal. It should be borne in mind that an error might be introduced by the fact that the total exit gas flow changes when some gas is produced by the reaction. With the assumption made above, the heat flow due to the product gas enthalpy is incorporated into $\phi_{\mathrm{Ch}}$.

The flow signal recorded by the apparatus, $\phi_{\mathrm{R}-\mathrm{REC}}$, is the difference between the sample thermopile signal $\phi_{\mathrm{R}}$ and the reference thermopile signal $\phi_{\mathrm{REF}}$. Thus, the recorded raw signal is:

$\phi_{\mathrm{R}-\mathrm{REC}}=\phi_{\mathrm{R}}-\phi_{\mathrm{REF}}$

1) List of symbols at the end of the paper. 
and the recorded blank signal is:

$\phi_{\mathrm{B}-\mathrm{REC}}=\phi_{\mathrm{B}}-\phi_{\mathrm{REF}}$

Substracting the recorded blank flow $\phi_{\mathrm{B}-\mathrm{REC}}$ from the recorded raw flow $\phi_{\mathrm{R}-\mathrm{REC}}$ gives the "recorded" net flow:

$\phi_{\mathrm{N}-\mathrm{REC}}=\phi_{\mathrm{R}-\mathrm{REC}}-\phi_{\mathrm{B}-\mathrm{REC}}=\left(M_{\mathrm{C}}+M_{\mathrm{s}}\right) \frac{\mathrm{d} T_{\mathrm{c}}}{\mathrm{d} t}+\phi_{\mathrm{Ch}}-M_{\mathrm{C}} \beta$

since the reference flow signal $\phi_{\mathrm{REF}}$ is the same during the experiment and during the blank test.

An enthalpy balance for the crucible + sample (domain $C$ in Fig. 1) gives:

$\left(M_{\mathrm{C}}+M_{\mathrm{s}}\right) \frac{\mathrm{d} T_{\mathrm{c}}}{\mathrm{d} t}+\phi_{\mathrm{Ch}}-\phi_{\mathrm{C}-\mathrm{F}}=0$

where $\phi_{\mathrm{C}-\mathrm{F}}$ is the exchanged flow between the crucible and the furnace.

Following assumption (c), the term $\phi_{\mathrm{C}-\mathrm{F}}$ will be expressed as:

$\phi_{\mathrm{C}-\mathrm{F}}=A \lambda_{\mathrm{f}}\left(T_{\mathrm{W}}-T_{\mathrm{C}}\right)$

where $A$ is a constant that characterizes the TG-DSC apparatus under the atmosphere flow conditions used, and $\lambda_{\mathrm{f}}$ is the thermal conductivity of the atmosphere gas. In the following, this conductivity will be assessed as a polynomial function of the furnace temperature. Eq. (5) shows that there exists a temperature difference due to heat transfer, $T D_{\mathrm{HT}}$, between the crucible and the furnace. This difference can be expressed from Eqs. (3), (4), and (5):

$\mathrm{TD}_{\mathrm{HT}}=\frac{\phi_{\mathrm{N}-\mathrm{REC}}+M_{\mathrm{c}} \beta}{A \lambda_{\mathrm{f}}}$

In addition, the heat flow measurement system globally introduces a response time $\tau_{\mathrm{HFM}}$ (see assumption (d)) which will be responsible for another temperature difference between the crucible and the furnace, $\mathrm{TD}_{\mathrm{HFM}}$ [9]. This term can be expressed from the flowmeter time delay $\tau_{\text {HFM }}$ and from the heating rate $\beta$ :

$\mathrm{TD}_{\mathrm{HFM}}=\tau_{\mathrm{HFM}} \beta$

Thus, the total temperature difference between the crucible and the furnace is:

$\mathrm{TD}=T_{\mathrm{f}}-T_{\mathrm{c}}=\mathrm{TD}_{\mathrm{HT}}+\mathrm{TD}_{\mathrm{HFM}}$

Moreover, the chemical reaction heat flow can be expressed as follows if the reaction heat $\Delta H$ is in $\mathrm{J} \mathrm{kg} \mathrm{lost}^{-1}$ :

$\phi_{\mathrm{Ch}}=\frac{\mathrm{d} m_{\mathrm{S}}}{\mathrm{d} t} \Delta H$

Finally, the net recorded flow can be rewritten from Eqs. (3) and (9):
$\phi_{\mathrm{N}-\mathrm{REC}}=\left(M_{\mathrm{C}}+M_{\mathrm{s}}\right) \frac{\mathrm{d} T_{\mathrm{c}}}{\mathrm{d} t}+\frac{\mathrm{d} m_{\mathrm{S}}}{\mathrm{d} t} \Delta H-M_{\mathrm{C}} \beta$

In Eq. (10), it appears that the net recorded flow is the sum of three separate heat flows. The method consists in calculating each of these flow contributions and in summing them to calculate a net flow $\phi_{\mathrm{N} \text {-c }}$. The unknown parameters $(\Delta H, c p, A)$ are determined by fitting $\phi_{\mathrm{N}-\mathrm{REC}}$ and $\phi_{\mathrm{N}-\mathrm{c}}$ on a standard experiment.

Then, TD can be calculated by adjusting $\tau_{\text {HFM }}$ with a second standard experiment.

\subsection{Experiments}

In the proposed method, the standard experiments are conducted with a reference material. $30 \mathrm{mg}$ of calcium oxalate are heated at $3 \mathrm{~K} \mathrm{~min}^{-1}$ (first experiment) and $30 \mathrm{~K} \mathrm{~min}^{-1}$ (second experiment) under a nitrogen atmosphere; the flow rate is $54 \mathrm{~mL} \mathrm{~min}^{-1}$ at STP conditions.

In the temperature range from 150 to $350{ }^{\circ} \mathrm{C}$, calcium oxalate undergoes a decomposition to carbonate, responsible for approximately $12 \%$ mass loss. The reaction heat is reported as $-400 \mathrm{~kJ} \mathrm{~kg} \mathrm{oxalate}^{-1}$, which is equivalent to $3.33 \mathrm{MJ} \mathrm{kg} \mathrm{lost}^{-1}$.

\section{Validation of the Model}

\subsection{Determination of Constants in Expression of $T D$}

The recorded net heat flow $\phi_{\mathrm{N}-\mathrm{REC}}$ and the DTG signal (derived directly from the mass signal by the apparatus software) are plotted in Fig. 2; they reveal a time shift of approximately $20 \mathrm{~s}$ between the peak values of the two signals. According to Eq. (9), the time shift between the two signals

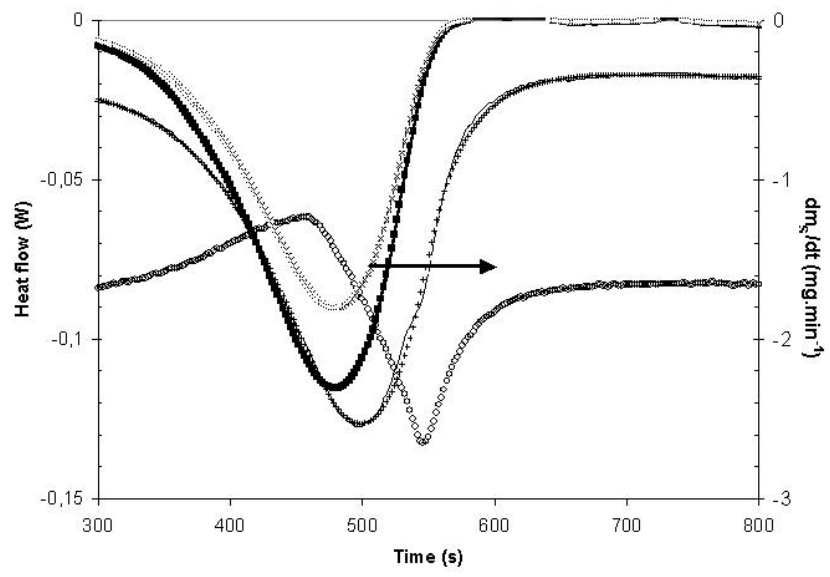

Figure 2. Time evolution for oxalate of $(+)$ the recorded net heat flow $\phi_{\mathrm{N}-\mathrm{REC}}$ $(\mathrm{W}),(\times)$ the sample mass derivative, $(-)$ the calculated net heat flow $\phi_{\mathrm{N}-\mathrm{c}}$ $(\mathrm{W}),(\mathbf{\square})$ the chemical reaction heat flow $\phi_{\mathrm{Ch}}(\mathrm{W}),(\mathrm{O})$ the crucible + sample inertia heat flow $\left(M_{\mathrm{C}}+M_{\mathrm{S}}\right) \mathrm{d} T_{\mathrm{C}} \mathrm{d} t(\mathrm{~W}),(\ldots)$ arbitrary base line for heat integration. 
is physically unsatisfactory, confirming that $\phi_{\mathrm{N}-\mathrm{REC}}$ includes inertia terms. It is also possible to calculate and to plot in Fig. 2 two of the three terms on the right-hand side of Eq. (10) since:

- If $A$ is fixed (initialization), the crucible temperature can be calculated from Eq. (6). $M_{\mathrm{C}}$ is known; $M_{\mathrm{S}}$ can be calculated from the sample mass $m_{\mathrm{S}}$ recorded during the test, if $c p_{\mathrm{S}}$ if fixed (initialization). The first term can then be calculated.

- The chemical reaction heat, the second term in Eq. (10), can be calculated if a reaction heat $\Delta H$ is fixed.

- For the third term, the thermal inertia of the crucible is a known constant.

A problem may arise due to the fact that three unknowns are to be fitted: $A, \Delta H$, and $c p_{\mathrm{s}}$. Nevertheless, they can be determined through a series of easy trials and adjusted for the three terms. Indeed:

- When the chemical reaction is over, the net flow $\phi_{\mathrm{N}-\mathrm{c}}$ is sensitive only to $c p_{\mathrm{S}}$. This specific heat is directly determined by fitting $\phi_{\mathrm{N}-\mathrm{c}}$ and $\phi_{\mathrm{N}-\mathrm{REC}}$ in the pre- or postreaction zone, which is a common way of measuring specific heat when no reaction occurs.

- $\Delta H$ acts on the peak intensity of $\phi_{\mathrm{N}-\mathrm{c}}$ and on the left-right position of the peak.

- $A$ only acts on the left-right position of the $\phi_{\mathrm{N}-\mathrm{c}}$ peak.

It is, therefore, possible to fix $\Delta H, A$, and $c p_{\mathrm{S}}$ separately. Several iterations lead to the $\phi_{\mathrm{N}-\mathrm{c}}$ curve in Fig. 2, deriving the values:

$A=0.140 \mathrm{~m}$

$\Delta H=-3.76 \mathrm{MJ} \mathrm{kg}^{-1}$

$c p_{\mathrm{S}}=1100 \mathrm{~J} \mathrm{~kg}^{-1} \mathrm{~K}^{-1}$

These values could be fitted without ambiguity within $\pm 2 \%$. The experimental net flow $\phi_{\mathrm{N}-\mathrm{REC}}$ was satisfactorily reconstructed from the sum of the three terms in Eq. (10) (see Fig. 2).

It is noteworthy that the inertia heat flow of the crucible + sample is important as compared with the chemical reaction heat flow $\phi_{\mathrm{Ch}}$, which makes it important to run a high quality blank test. Calculating $M_{\mathrm{C}}$ and $M_{\mathrm{S}}$ indicates that the sample is responsible for only approximately $1 \%$ of the total inertia.

Concerning oxalate, it is assumed that the chemical reaction follows first-order kinetics. It is then possible to calculate the reaction rate $k$ at each temperature from Eq. (11) since $\mathrm{d} m / \mathrm{d} t$ and $m$ are known:

$\frac{\mathrm{d} m}{\mathrm{~d} t}=-k m=-A_{0} \exp ^{-\frac{E}{R T}} m$

where $m$ is the reactive remaining mass, or $m_{\mathrm{s}}-m_{\text {final }}$.

The values of $k$ along the test performed at $30 \mathrm{~K} \mathrm{~min}^{-1}$, and those for the test performed at $3 \mathrm{~K} \mathrm{~min}^{-1}$, using the furnace temperature in the abscissa $\left(1 / T_{\mathrm{f}}\right)$ are plotted in Fig. 3a). The plot exhibits straight lines, which indicates that the first-order kinetics is a suitable model to describe the reaction. Nevertheless, large differences in values of $k$ for a given temperature are observed, due to the error introduced
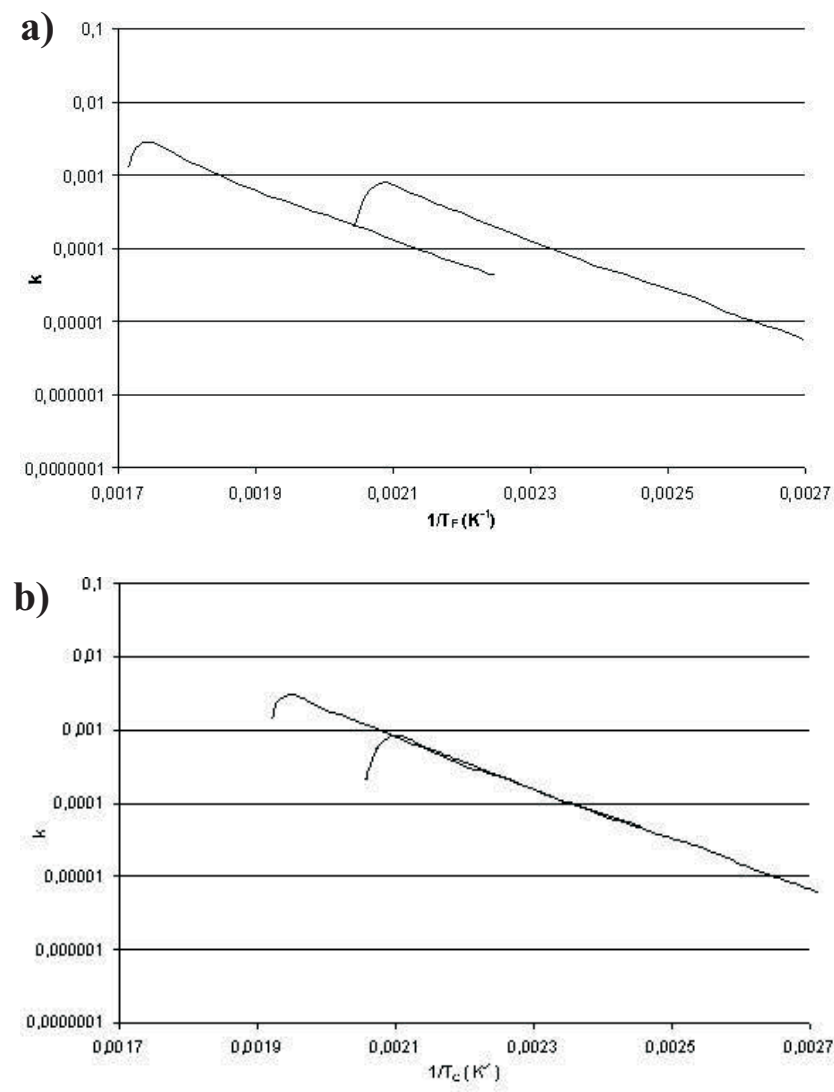

Figure 3. Reaction rate for decomposition to carbonate of calcium oxalate reaction during experiments with heating rates of $(-) 3 \mathrm{~K} \mathrm{~min}^{-1}$ and $(-)$ $30 \mathrm{~K} \mathrm{~min}^{-1}$. (a) Abscissa is $1 / T_{\mathrm{f}}$, (b) $1 / T_{\mathrm{C}}$ with $T_{\mathrm{c}}=T_{\mathrm{f}}-\mathrm{TD}$ and $\tau_{\mathrm{HFM}}=12 \mathrm{~s}$.

by the use of the furnace temperature instead of the actual sample temperature. As $\phi_{\mathrm{N}-\mathrm{c}}$ is not sensitive to $\tau_{\mathrm{HFM}}$, (that appears only in Eq. (7)), it is possible to completely reconcile the reaction rates obtained at two heating rates (see Fig. $3 b)$ ), using a value of $12.0 \mathrm{~s}$ for $\tau_{\mathrm{HFM}}$.

The temperature correction that finally has to be applied is:

$\mathrm{TD}=T_{\mathrm{f}}-T_{\mathrm{c}}=\frac{\phi_{\mathrm{N}-\mathrm{REC}}+M_{\mathrm{c}} \beta}{0.140 \lambda_{\mathrm{g}}}+12.0 \beta$

The temperature difference TD of the crucible towards the furnace during the two experiments can reach a value as high as $35^{\circ} \mathrm{C}$ during the test at $30 \mathrm{~K} \mathrm{~min}^{-1}$. The TD during the test at $3 \mathrm{~K} \mathrm{~min}^{-1}$ is much lower but still not negligible. It has to be noticed that, assuming the chemical reaction heat flow $\phi_{\mathrm{Ch}}$ is set equal to zero, TD significantly decreases with increasing furnace temperature, this being only due to the increase in $\lambda_{\mathrm{f}}$ with temperature.

\subsection{Validation of Method}

At first, the constants determined through the procedure have a physical meaning: 
- The calculated chemical reaction heat flow signal $\phi_{\mathrm{Ch}}$ is time-synchronized with the mass derivative, which satisfies the basic physical concept of reaction heat in Eq. (9).

- The reaction heat derived is equal (within the fitting error, or $\pm 2 \%$ ) to that given by the classical integration of the surface between the net flow curve $\phi_{\mathrm{N}-\mathrm{REC}}$ and the base line represented in Fig. 2.

- The value of 1100 for the sample-specific heat $c p_{\mathrm{S}}$ is a suitable value.

To check the validity of the calculation of TD, two additional tests with heating rates of 15 and $50 \mathrm{~K} \mathrm{~min}^{-1}$ were performed. In Fig. 4, the values of the reaction rate $k$ from the experiments at $3,15,30$ and $50 \mathrm{~K} \mathrm{~min}^{-1}$ were plotted versus the reverse of the crucible temperature calculated using the expression of TD in Eq. (13). Whatever the heating rate operated, the values of $k$ are very similar; this attests for the good description of TD.

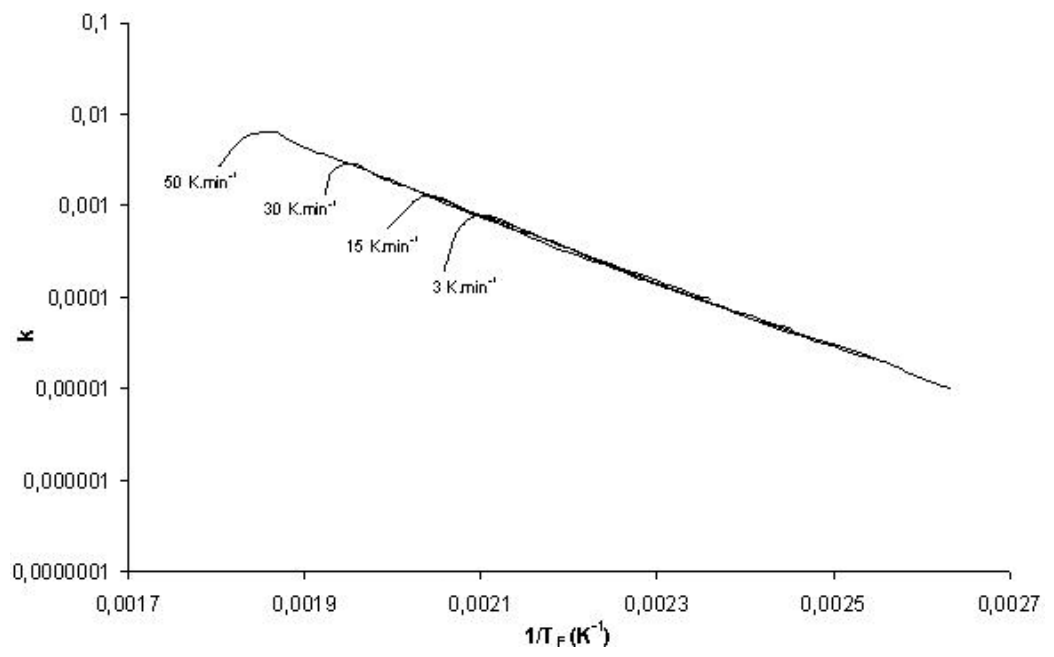

Figure 4. Reaction rate for monoxide release from calcium oxalate reaction during experiments with heating rates of $3,15,30$, and $50 \mathrm{~K} \mathrm{~min}^{-1}$ versus sample corrected temperature.

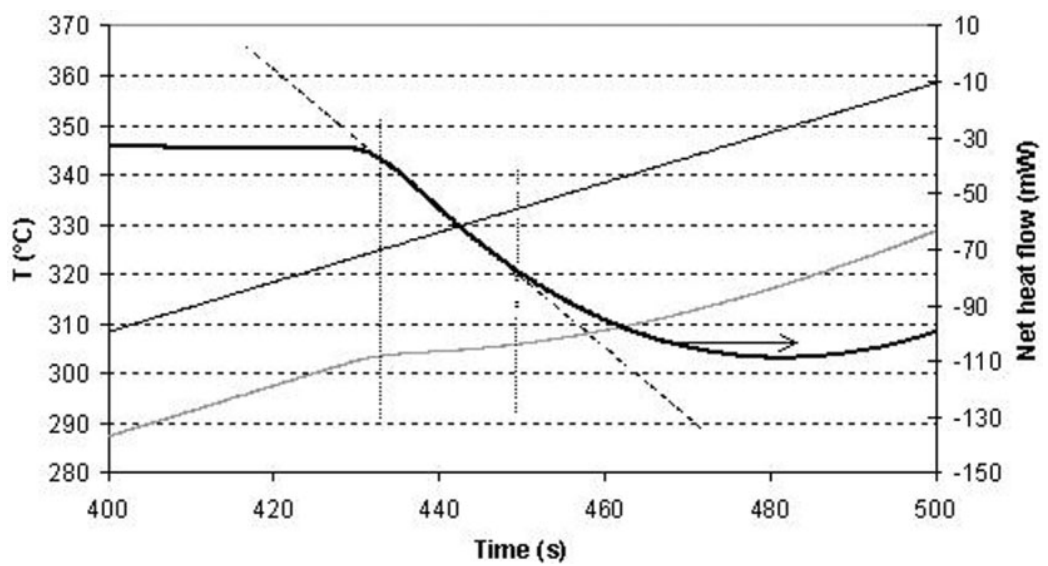

Figure 5. Temperature of furnace (-) and calculated temperature for crucible (-) during transition reaction of potassium perchlorate, under nitrogen, at $30 \mathrm{~K} \mathrm{~min}^{-1}$. (-) Net recorded heat flow $\phi_{\mathrm{N}-\mathrm{REC}}$ versus time. Vertical line indicates linear zone of heat flow.
Finally, another validation test was performed with potassium perchlorate. This calibration material is reported to undergo a transition at the reference temperature of $300^{\circ} \mathrm{C}$. The transformation occurs without mass change of the sample. The product was heated at $30 \mathrm{~K} \mathrm{~min}^{-1}$, under a $54 \mathrm{~mL} \mathrm{~min}^{-1}$ flow of $\mathrm{N}_{2}$. Fig. 5 illustrates the evolution of the furnace temperature and that of the crucible, calculated using the expression of TD derived previously. The net recorded heat flow has also been plotted. It is generally admitted that the period where a transition occurs or where the smelting of a metal is isothermal, is the period during which the heat flow curve is linear. This zone is indicated in the figure thanks to two vertical dotted lines. During this period, the calculated temperature of the crucible indicates a plateau around $305^{\circ} \mathrm{C}$. This value is very close to the reference temperature of $300^{\circ} \mathrm{C}$, while, during the same period, the furnace temperature is between 325 and $332^{\circ} \mathrm{C}$. The correction using TD appears to give a much better estimation of the actual sample temperature.

\section{Conclusion}

It is possible to derive a simple mathematical expression to calculate the actual crucible. This expression requires the recorded net heat flow data and the heating rate as inputs plus a number of constants that characterize the TG-DSC mounting, whose method of determination has been detailed. This determination necessitates conduction of two simple experiments with different heating rates, and a simple posttreatment of the data in a series of manual trials to adjust four parameters whose independence has been checked. For clarity, the procedure is summarized in the appendix.

The method can be generalized to other TG-DSC mountings in which the crucible is separated from the heating source by an air film. In the case of the apparatus used here and a standard $5 \mathrm{~mm}$ outer diameter platinum crucible, the expression for the temperature difference between the crucible and the furnace is:

$\mathrm{TD}=T_{\mathrm{f}}-T_{\mathrm{c}}=\frac{\phi_{\mathrm{N}-\mathrm{REC}}+M_{\mathrm{c}} \beta}{0.140 \lambda_{\mathrm{g}}}+12.0 \beta$

where $\phi_{\mathrm{N}-\mathrm{REC}}$ is the blank corrected heat flow and $\beta$ the heating rate.

The decomposition of the net heat flow into a sum of identified heat flows also has the advantage of leading to the determination of the reaction heat and of the sample specific heat. This and other considerations 


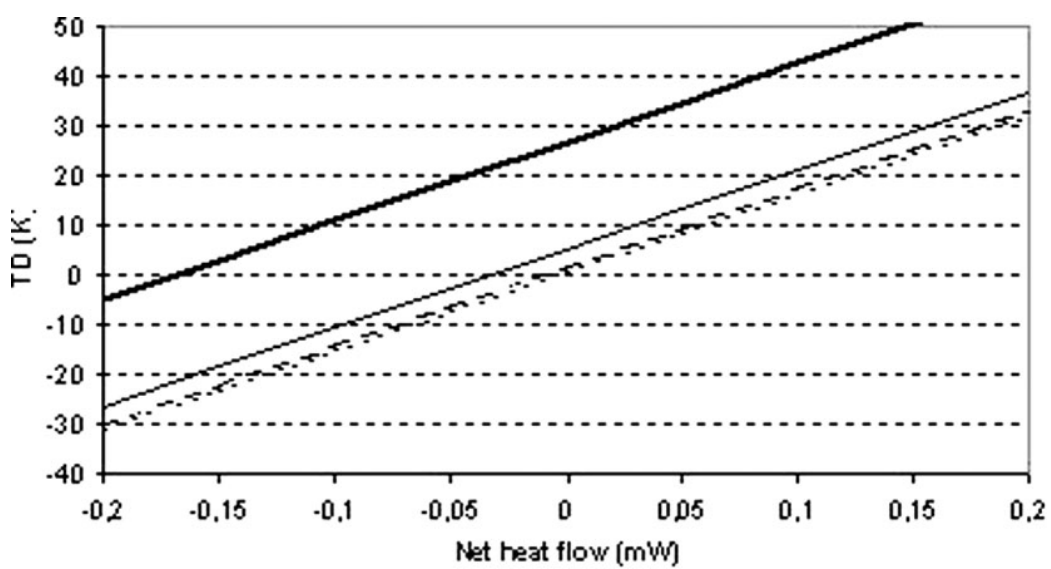

Figure 6. General plot of temperature difference TD between furnace and crucible (-) versus recorded net heat flow $\phi_{\mathrm{N}-\mathrm{REC}}$ during any experiment with a heating rate of (..) $1 ;(--) 3 ;(-) 10$, and (-) $50 \mathrm{~K} \mathrm{~min}^{-1}$. The curves are established for a SETARAM TG-DSC111 apparatus with the crucible used in all experiments presented in this paper.
Subscripts

$\begin{array}{ll}\text { B } & \text { blank } \\ \text { c } & \text { calculated } \\ \text { C } & \text { crucible } \\ \text { Ch } & \text { chemical reaction } \\ \text { cond } & \text { conduction } \\ \text { f } & \text { furnace } \\ \text { g } & \text { atmosphere gas } \\ \text { N } & \text { net } \\ \text { R } & \text { raw } \\ \text { rad } & \text { radiation } \\ \text { REC } & \text { recorded } \\ \text { S } & \text { sample } \\ \text { HT } & \text { heat transfer } \\ \text { HFM } & \text { heat flowmeter } \\ \text { W } & \text { wall's furnace }\end{array}$

enable the physical meanings to be ascribed to the derived mathematical expression.

For practical purposes, Fig. 6 established from the mathematical expression gives the temperature difference between the crucible and the furnace as a function of the net heat flow (given by the apparatus along an experiment) for different heating rates. It confirms the necessity in most of the cases to operate a furnace temperature correction such as the one studied here.

Finally, for oxalate, it is shown that the expression of TD to calculate the sample temperature allows derivation of similar reaction rates for a first-order kinetic reaction over a wide range of heating rates: 3 to $50 \mathrm{~K} \mathrm{~min}^{-1}$.

Received: January 17, 2006

\section{Symbols used}

$\begin{array}{ll}A & {[\mathrm{~m}]} \\ c p & {\left[\mathrm{~J} \mathrm{~kg}^{-1} \mathrm{~K}^{-1}\right]} \\ D & {[\mathrm{~m}]} \\ k & {\left[\mathrm{~s}^{-1}\right]} \\ l & {[\mathrm{~m}]} \\ m & {[\mathrm{~kg}]} \\ M & {\left[\mathrm{~J} \mathrm{~K}^{-1}\right]} \\ S & {\left[\mathrm{~m}^{2}\right]} \\ T & {[\mathrm{~K}]} \\ \text { TD } & {[\mathrm{K}]}\end{array}$

\section{Greek letters}

$\begin{array}{ll}\phi & {[\mathrm{W}]} \\ \beta & {\left[\mathrm{K} \mathrm{s}^{-1}\right]} \\ \lambda & {\left[\mathrm{W} \mathrm{m}^{-1} \mathrm{~K}^{-1}\right]} \\ \varepsilon & {[-]} \\ \tau & {[-]} \\ \Delta H & {\left[\mathrm{~J} \mathrm{~kg}^{-1}\right]}\end{array}$

heat flow heating rate thermal conductivity emissivity characteristic time constant chemical reaction heat
This paper's data

$m_{\mathrm{c}}=9.6610^{-4} \mathrm{~kg}$

$c p_{\mathrm{C}}=133 \mathrm{~J} \mathrm{~kg}^{-1} \mathrm{~K}^{-1}$

$S_{\mathrm{c}}=1.77010^{-4} \mathrm{~m}^{2}$ (crucible belt + bottom $)$

$\varepsilon_{\mathrm{C}}=0.25$

$\varepsilon_{\mathrm{f}}=0.3$

\section{References}

[1] C. David, S. Salvador, J. L. Dirion, M. Quintard, J. Anal. Appl. Pyrol. 2003, 67 (2), 307.

[2] I. Milosavljevic, V. Oja, V. Suuberg, Ind. Eng. Chem. Res. 1996, 35, 653.

[3] J. A. Conesa, A. Marcilla, R. Moral, J. Moreno-Caselles, et al., Thermochim. Acta 1998, 313, 63 .

[4] J. S. Subramanian, P. K. Gallagher, Thermochim. Acta 1995, 269/270, 89

[5] K. Sigrist, P. K. Stach, Thermochim. Acta 1996, 278, 145.

[6] P. K. Dong, P. K. Hunt, in Proc. of the $14^{\text {th }}$ Symp. on Thermophysical Properties, Boulder, CO, USA, 2000.

[7] J. H. Ferrasse, Ph.D. Thesis, Ecole des Mines d'Albi-Carmaux, France 2000.

[8] F. P. Incropera, D. P. DeWitt, Fundamentals of Heat and Mass Transfer, $4^{\text {th }}$ ed., John Wiley \& Sons, New York 1996.

[9] E. Calvet, H. Prat, Microcalorimétrie. Applications Physico-Chimiques et Biologiques, Masson \& Cie, Paris 1956.

[10] R. Siegel, J. R. Howel, Thermal Radiation Heat Transfer, $3^{\text {rd }}$ ed., Taylor \& Francis, London 1992.

\section{Appendix}

Summary of the procedure

- Run two experiments with $30 \mathrm{mg}$ of calcium oxalate under nitrogen at 3 and $30 \mathrm{~K} \mathrm{~min}^{-1}$.

- Run the blanks.

- Calculate the recorded net heat flows $\phi_{\mathrm{N}-\mathrm{REC}}$ (classical correction of an experiment with a blank test).

- Plot on the same graph $\phi_{\mathrm{N}-\mathrm{REC}}$ for the experiment at $30 \mathrm{~K} \mathrm{~min}^{-1}$ and $\phi_{\mathrm{N}-\mathrm{c}}$, sum of the terms on the right-hand side of Eq. (10), e.g.: 
$-\left(M_{\mathrm{C}}+M_{\mathrm{s}}\right) \frac{\mathrm{d} T_{c}}{\mathrm{~d} t}$ where $\frac{\mathrm{d} T_{c}}{\mathrm{~d} t}$ is obtained deriving numerically $T_{\mathrm{C}}$.

with $T_{\mathrm{C}}=T_{\mathrm{F}}-\mathrm{TD}$

where

$\mathrm{TD}=\mathrm{TD}_{\mathrm{HT}}+\mathrm{TD}_{\mathrm{HFM}}=\frac{\phi_{\mathrm{N}-\mathrm{REC}}+M_{\mathrm{c}} \beta}{A \lambda}+\tau_{\mathrm{HFM}} \beta$ in which $A, c p_{\mathrm{S}}$ (in $M_{\mathrm{S}}$ ), and $\tau_{\mathrm{HFM}}{ }^{A}{ }^{\lambda} \mathrm{e}^{\mathrm{g}}$ initialized (see results presented in this paper);

- $\phi_{C h}=\frac{d m_{S}}{d t} \Delta H$ in which $\Delta H$ is initialized;

- $M_{\mathrm{C}} \beta$ is a known constant.

- Adjust $c p_{\mathrm{S}}, A$ and $\Delta H$ to fit with $\phi_{\mathrm{N}-\mathrm{c}}$ and $\phi_{\mathrm{N}-\mathrm{REC}}$.

- Plot on the same graph the values of $k$ versus $1 / T_{\mathrm{C}}$ (see Fig. 3(b)) for the two experiments at 3 and $30 \mathrm{~K} \mathrm{~min}^{-1}$, $\left(T_{\mathrm{C}}=T_{\mathrm{f}}-\mathrm{TD}\right)$.

- adjust $\tau_{\mathrm{HFM}}$ to reconcile the two curves for $k$.

The expression

$\mathrm{TD}=T_{\mathrm{f}}-T_{\mathrm{c}}=\frac{\phi_{\mathrm{N}-\mathrm{REC}}+M_{\mathrm{c}} \beta}{A \lambda_{\mathrm{g}}}+\tau_{\mathrm{HFM}} \beta$

is fully determined.

\section{Annex 1}

To calculate the equivalent heat transfer coefficient at the surface of the crucible $h$, the resistance between the crucible and the surroundings can be expressed as follows, using the crucible outside surface $S_{\mathrm{c}}$ (wall + bottom):

$R_{\mathrm{C}-\mathrm{f}}=\frac{1}{h S_{\mathrm{c}}}$

The two expressions of the resistance in Eqs. (15) and (16) lead to $h=31.5 \mathrm{~W} \mathrm{~m}^{-2} \mathrm{~K}^{-1}$.

The validity of the assumption of conductive heat transfer between the crucible and the furnace wall was checked by running an experiment at $30 \mathrm{Kmin}^{-1}$ with a different $\mathrm{N}_{2}$ flow: $20 \mathrm{~mL} \mathrm{~min}^{-1}$ at STP conditions. The value of constant $A$ fitted from this experiment was again 0.14 . The fact that the heat transfer coefficient does not depend upon the flow velocity attests for the mainly conductive - and not convective - nature of the heat transfer.

The contribution of radiation to the heat exchange between the crucible and the furnace wall can be estimated at this stage. The global heat transfer coefficient $h$ can be expressed as the sum of a conduction heat transfer $h_{\text {cond }}$ and of a radiation heat transfer $h_{\text {rad }}$ :

$h=h_{\text {cond }}+h_{\text {rad }}$

The value of $h_{\text {rad }}$ can be estimated from the following two expressions of the radiative heat flow between the furnace and the crucible:

$\varepsilon_{\mathrm{f}} \varepsilon_{\mathrm{c}} \sigma\left(T_{\mathrm{f}}^{4}-T_{\mathrm{c}}^{4}\right)=h_{\mathrm{rad}}\left(T_{\mathrm{f}}-T_{\mathrm{c}}^{4}\right)$

where the emissivities $\varepsilon_{\mathrm{f}}$ and $\varepsilon_{\mathrm{f}}$ are taken from [10], and $\sigma$ is the Boltzmann constant. At the reaction peak, for instance, the furnace temperature is $T_{\mathrm{f}}=275^{\circ} \mathrm{C}$ and the crucible temperature is $T_{\mathrm{c}}=311^{\circ} \mathrm{C}$. This gives a value for $h_{\mathrm{rad}}$ of $3.09 \mathrm{~W} \mathrm{~m}^{-2} \mathrm{~K}^{-1}$. This shows, by comparison with the global heat transfer coefficient $h=31.5 \mathrm{~W} \mathrm{~m}^{-2} \mathrm{~K}^{-1}$, that the contribution of radiation in this range of temperature is small.

As far as the heat transfer between the crucible and the furnace is concerned, a reference can be found in terms of the equivalent conduction resistance to cross the atmosphere gas film separating the crucible and the furnace wall. This resistance can be expressed in cylindrical geometry:

$R_{\text {cond }}=\frac{1}{2 \pi \lambda_{\mathrm{f}} l} \ln \frac{D_{\mathrm{f}}}{D_{\mathrm{C}}}$

At the reaction peak intensity, for example, where $T_{\mathrm{f}}=275^{\circ} \mathrm{C}$ and $\lambda_{\mathrm{f}}=0.0436 \mathrm{~W} \mathrm{~m}^{-1} \mathrm{~K}^{-1}$, its value is $143 \mathrm{~K} \mathrm{~W}^{-1}$. On the other hand, Eq. (5) is equivalent to:

$R=\frac{1}{A \lambda_{\mathrm{f}}}$

With the fitted value $A=0.140$, this gives $R=164 \mathrm{~K} \mathrm{~W}^{-1}$. The similarity in the values of $R$ and $R_{\text {cond }}$ attests for the physical significance of the value of $A$ that was fitted. 